\title{
Association of all forms of malnutrition and socioeconomic status, educational level and ethnicity in Colombian children and non-pregnant women
}

\author{
Gustavo Cediel ${ }^{1, *} \odot$, Eliana Perez ${ }^{1}$, Diego Gaitán ${ }^{1}$, Olga L Sarmiento² and \\ Laura Gonzalez ${ }^{1}$ (1) \\ 'Escuela de Nutrición y Dietética, Universidad de Antioquia, UdeA Calle 70 No. 52-21, Medellín, Colombia: ${ }^{2}$ School \\ of Medicine, Universidad de los Andes, Bogotá, Colombia
}

Submitted 7 January 2019: Final revision received 18 August 2019: Accepted 4 October 2019: First published online 5 March 2020

\begin{abstract}
Objective: To examine the association of all forms of malnutrition and socioeconomic status (SES), educational level and ethnicity in children $<5$ years, nonpregnant adolescent women (11-19 years) and non-pregnant adult women (20-49 years) in Colombia.

Design: Cross-sectional analysis of data from the 2010 Colombian National Nutrition Survey. The prevalence of malnutrition was compared across categories of SES, educational level and ethnicity.

Setting: Colombia.

Participants: The sample for the current analysis comprised children $<5$ years, non-pregnant adolescent women (11-19 years) and non-pregnant adult women (20-49 years).

Results: In children < 5 years, a low SES and maternal educational level were significantly associated with a lower prevalence of overweight/obesity compared with high levels of SES and maternal education, that is, the prevalence of overweight/obesity was 1.4 and 1.6 times lower in categories of low SES and educational levels, respectively. In contrast, the prevalence of wasting, stunting and anaemia was higher in the lowest SES and maternal educational categories (the prevalence was between 1.1 and 1.8 times higher for these indicators). In women, the lowest SES (11 and 19 years) and educational levels (20 and 49 years) exhibited a higher prevalence in all forms of malnutrition compared with their counterparts in the highest categories (i.e. overweight/obesity, stunting and anaemia). Additionally, indigenous or Afro-Colombian children and women had the highest prevalence of malnutrition in comparison with other ethnicities.

Conclusions: These results suggest that public policies should address all forms of malnutrition that occur in the most vulnerable populations in Colombia using multiple strategies.
\end{abstract}

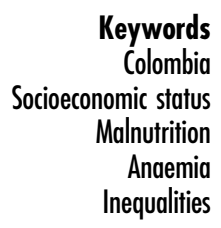

Morbidities associated with energy intake (deficiency and excess) are prevalent worldwide. By the year 2015, 2 million adults were overweight, and 462 million were underweight. Furthermore, 42 million preschool children were overweight, and 156 million were affected by nutritional stunting ${ }^{(1)}$. Micronutrient deficiencies are still a public health concern. For example, the globally estimated prevalence of anaemia in children, pregnant women and women of reproductive age are $42.6,38.2$ and $29.0 \%$, respectively; furthermore, between 42 and $50 \%$ of anaemia cases may be alleviated by prevention programmes ${ }^{(2)}$. Thus, nutrition associated with public health problems has two concomitant factors (under- and overnutrition) that can be recognised as a double burden of malnutrition (DBM) ${ }^{(1)}$. The United Nations General Assembly proclaimed the years 2016-2025 as the Decade of Nutrition. One of the aims of this UN declaration

Disclaimer: This paper was published as part of a Supplement in the Journal of Public Health Nutrition, publication of which was supported partially by SLAN CAPÍTULO MEXICO A.C. The papers included in this supplement were invited by the Guest Editor and have undergone the standard journal formal review process. They may be cited. 
includes 'catalyzing and facilitating alignment of on-going efforts of multiple actors from all sectors, including new and emerging actors, to foster a global movement to end all forms of malnutrition and leaving no one behind ${ }^{\text {(3) }}$.

According to a social epidemiological perspective, socioeconomic status (SES) is a combined economic and sociological measure of a person's work experience and of an individual's or family's economic and social position in relation to others. This definition examines household income, earners' educational level and occupation, as well as combined incomes, whereas for an individual's SES, only their own attributes are assessed. However, SES is more commonly used to depict an economic difference in society as a whole $\mathrm{e}^{(4,5)}$. In this case, it is important to elucidate how low SES and education have been shown to be strong predictors of a range of nutritional problems in vulnerable age groups (e.g. children and non-pregnant adolescent and adult women $)^{(6,7)}$.

In this way, recent studies showed that low SES was associated with a reduction in life expectancy and premature mortality, mainly from diet-related to non-communicable diseases (e.g. obesity, diabetes and hypertension) ${ }^{(8-10)}$. These studies suggested that individual factors (education, occupation and income) were affected by external factors that generate stratifications or status in both individual and population health. This issue radically affects the formulation of economic, social and health policies because this approach should come from the determinants of health rather than from purely economic interventions ${ }^{(11)}$. The study of the association between SES and malnutrition is especially relevant for Latin America, where economic growth, rapid urbanisation and an increase in inequality with subsequent transformation of the food system have been observed ${ }^{(12,13)}$. These conditions represent challenges to improving nutrition in the region ${ }^{(14,15)}$.

In Colombia, positive economic growth has been occurring and is indicated by a positive gross domestic product (GDP) index. However, GDP has varied from $2.0 \%$ in the fourth quarter of 2016 to just $1 \cdot 1 \%$ in the first quarter of $2017^{(16)}$. In addition, economic inequity may be high, as the national GINI index of 2016 was 0.517 , with 0.495 in urban zones and 0.458 in rural zones ${ }^{(17)}$. Colombia is experiencing a nutritional transition as well ${ }^{(6)}$, where both facets of the DBM are evident. Nutritional stunting affects $13.2 \%$ (95\% CI: $12.5,13.9)$ of preschool children, while $20.2 \%$ (95\% CI: 19.4, 21.0) are at risk of being overweight, and $10.6 \%$ (95\% CI: 9.3, 12.0) suffer from iron deficiencies $^{(18)}$. Preliminary research suggests that a low to high prevalence of overweight and obesity (3.4-51.2\%) co-exist with a moderate to high prevalence of anaemia (8.1-27.5\%) and stunting (13.2\%). However, the relationship between socioeconomic determinants (i.e. SES, educational level and ethnicity) and malnutrition is limited to a single study conducted over a decade ago, and education and ethnicity have not been evaluated in combination with malnutrition in Colombia ${ }^{(19,20)}$. Because of the historic civil conflict has promoted segregation and internal displacement of indigenous and Afro-Colombian communities, it is important to explore the association between these variables and nutritional problems; independent of other SES approximations ${ }^{(21,22)}$. Thus, the objective of the current study was to examine the association of all forms of malnutrition and SES, educational level and ethnicity in children $<5$ years and non-pregnant women in Colombia.

\section{Methods}

\section{Data source and sampling}

Our analysis used cross-sectional representative data from the 2010 Colombian Demographic and Health Survey ((Encuesta Nacional de Demografía y Salud (ENDS)) and the National Nutritional Survey (Encuesta Nacional de la Situación Nutricional en Colombia (ENSIN)), acronyms are in Spanish, were collected at the same time (simultaneously) to the same persons ${ }^{(18,23)}$. These surveys applied a multistage, population-based sampling design stratified by clusters (house-hold segments) that included 50670 households to obtain national and sub-regional representativeness (sixteen sub-regions), with oversampling of rural areas and low-wealth groups that covered $99 \%$ of the population. The response rate for anthropometric measurements was $85 \%$ of the sample population between 0 and 64 years ${ }^{(18)}$. The sample for the current analysis comprised 19734 children $<5$ years, 16831 women between 11 and 19 years and 44051 women between 20 and 49 years. The Profamilia Institutional Review Board on Research involving Human Subjects and the Colombian National Institutes of Health granted local ethical approval for the current study.

\section{Evaluation of malnutrition}

During ENDS/ENSIN ${ }^{(18,23)}$, weight and height were measured with standardised equipment. Weight was measured to the nearest $0 \cdot 1 \mathrm{~kg}$ using a digital weighing scale (SECA model 770), and participants were instructed to wear light clothing and remove their shoes. Height was measured to the nearest $0 \cdot 1 \mathrm{~cm}$ with a portable stadiometer (Shorr Productions), and length was measured in children 2 years or younger in a prone position following established protocols $^{(24,25)}$. Hb was measured by the Hemocue method (HemoCue $\mathrm{AB}$ ) and adjusted according to altitude, and tobacco use was measured as recommended by the International Nutritional Anaemia Consultative Group ${ }^{(26)}$.

The criteria for malnutrition were as follows: overweight: BMI-for-age $z$ score $>2$ and $\leq 3$ for children $<5$ years; BMIfor-age $z$ score $>1$ and $\leq 2$ for women $11-19$ years and BMI $\geq 25$ and $<30$ for women $20-49$ years. Obesity: BMI-for-age $z$ score $>3$ for children $<5$ years; BMI-for-age $z$ score $>2$ for women 11-19 years and BMI $\geq 30$ for women $20-49$ years. Excess weight (overweight/obesity) in children $<5$ years: BMI for age $z$-score $>2$; non-pregnant adolescent women 11-19 years: BMI for age $z$-score $>1$; non-pregnant adult 
women $20-49$ years: BMI $\geq 25 \mathrm{~kg} / \mathrm{m}^{2}$. Wasting/underweight in preschools: weight for age $z$-score $<-2$; non-pregnant adolescents $11-19$ years: BMI for age $z$-score $<-2$ : nonpregnant adult women 20-49; BMI $<18.5 \mathrm{~kg} / \mathrm{m}^{2}$. Stunting/ short stature in preschools: height for age $z$-score $<-2$; non-pregnant adolescents 11-19 years height for age $z$-score $<-2$; non-pregnant adults 20-49: height $<1.49 \mathrm{~m}^{(27,28)}$. Among children 6-59 months, anaemia was defined as $\mathrm{Hg}$ $<110 \mathrm{~g} / \mathrm{l}$ and in non-pregnant women $\mathrm{Hg}<120 \mathrm{~g} / \mathrm{l}^{(26)}$.

\section{Sociodemographic characteristics and} socioeconomic status

The sociodemographic characteristics collected included sex, age category (children < 5 years, non-pregnant adolescent women 11-19 years and non-pregnant adult women 20-49 years), ethnicity (indigenous, Black/ Mulatto/Afro-Colombian and other ethnicities identified by self-reporting) and level of education 0-6years (elementary or basic school), 7-12 years (secondary school) and $>12$ years (high school). SES was assessed by using the Sistema de Identificación de Potenciales Beneficiarios de Programas Sociales (SISBEN; the Spanish acronym for Identification System for Potential Beneficiaries of Social Programs). The SISBEN III is an indicator of SES designed by the Colombian Government to identify families who might benefit from social programs, it is built from the dimensions of health, education, housing and individual vulnerability ${ }^{(29)}$. The information was collected by questionnaire, which was sent to adult family members and households. The collected information was classified into one of six levels. The population who fell in the lower levels of the SISBEN index were considered vulnerable and prioritised for the state's economic and social programmes.

\section{Statistical analysis}

The sociodemographic characteristics were described as a percentage and prevalence ( $95 \%$ CIs) by age groups.
In supplementary analysis, SES was divided into three categories: low SES (SISBEN index 1), medium SES (SISBEN index 2-3) and high SES (SISBEN index 4-6). To analyse household characteristics by SES, a linear trend test was used. We compared the prevalence of over- and undernutrition indicators by SES, educational level and race/ethnicity using linear adjusted combinations of the estimates (lincom function on Stata) (unadjusted estimates were described as supplementary material). For all analyses, a $P<0.05$ was considered statistically significant. Individual sample weights were applied to all analyses using the survey prefix command (SVY) to account for the design of the study. The Stata 15 program (StataCorp) was used to conduct the analyses.

\section{Results}

\section{Sociodemographic characteristics of the population by age groups in Colombia}

Table 1 shows the characteristics of the population by age groups. In children $<5$ years, non-pregnant adolescent women (11-19 years) and non-pregnant adult women (20-49 years), most of the individuals lived in low SES, presented medium education level and were classified in other ethnicity categories than indigenous and AfroColombian. Supplementary Table 1 shows the percentage of the indigenous population in the low SES category was 2.7 times higher than that in the high SES category. Similarly, the percentage of Blacks/Mulatos/Afro-Colombian in the low SES category was $2 \cdot 1$ times higher than that in the highest SES category. Adult, non-pregnant women in the low SES category exhibited a prevalence of low educational levels that was six times higher than women in the high SES category, at 54.9 and $9.1 \%$, respectively. A significant linear trend was observed among all characteristics of households by SES categories.

Table 1 Sociodemographic characteristics of the population by age groups in Colombia (ENSIN 2010)

\begin{tabular}{|c|c|c|c|c|c|c|}
\hline & \multicolumn{6}{|c|}{ Age groups } \\
\hline & \multicolumn{2}{|c|}{ Children $<5$ years } & \multicolumn{2}{|c|}{ Women (11-19 years) } & \multicolumn{2}{|c|}{ Women (20-49 years) } \\
\hline & $\%$ & $95 \% \mathrm{Cl}$ & $\%$ & $95 \% \mathrm{Cl}^{*}$ & $\%$ & $95 \% \mathrm{Cl}$ \\
\hline \multicolumn{7}{|l|}{ Socioeconomic status } \\
\hline Low (sisben 1) & 50.5 & $49 \cdot 2,51 \cdot 9$ & $45 \cdot 8$ & $44 \cdot 6,47 \cdot 1$ & $32 \cdot 8$ & $31.9,33.7$ \\
\hline Medium (sisben 2-3) & $23 \cdot 2$ & $22 \cdot 2,24 \cdot 2$ & 22.4 & $21 \cdot 6,23 \cdot 2$ & $23 \cdot 2$ & $22 \cdot 6,23 \cdot 8$ \\
\hline High (sisben 4 or +) & $26 \cdot 3$ & $25 \cdot 1,27 \cdot 4$ & 31.7 & $30 \cdot 6,32 \cdot 8$ & $44 \cdot 0$ & $43 \cdot 0,45 \cdot 0$ \\
\hline \multicolumn{7}{|l|}{ Educational level } \\
\hline Low (0-6 years) & $27 \cdot 1$ & $26 \cdot 0,28 \cdot 3$ & $29 \cdot 8$ & $28 \cdot 9,30 \cdot 7$ & $36 \cdot 5$ & $35 \cdot 7,37 \cdot 2$ \\
\hline Medium (7-12 years) & $53 \cdot 8$ & $52 \cdot 6,54 \cdot 9$ & $59 \cdot 1$ & $58 \cdot 1,60 \cdot 0$ & $41 \cdot 2$ & $40.5,41.9$ \\
\hline High (>12 years) & $19 \cdot 1$ & $18 \cdot 1,20 \cdot 1$ & $11 \cdot 2$ & $10 \cdot 6,11 \cdot 8$ & $22 \cdot 3$ & $21 \cdot 6,23 \cdot 1$ \\
\hline \multicolumn{7}{|l|}{ Ethnicity } \\
\hline Indigenous & 4.7 & $4 \cdot 1,5 \cdot 3$ & 4.3 & $3 \cdot 8,4 \cdot 8$ & 4.0 & $3 \cdot 6,4 \cdot 3$ \\
\hline Black/Mulatto/Afro-Colombian & $11 \cdot 3$ & $10 \cdot 5,12 \cdot 2$ & $11 \cdot 1$ & $10.4,11.9$ & $10 \cdot 1$ & $9 \cdot 6,10 \cdot 7$ \\
\hline Other ethnicity & $84 \cdot 0$ & $83 \cdot 0,84 \cdot 9$ & 84.5 & $83 \cdot 7,85 \cdot 4$ & $85 \cdot 9$ & $85 \cdot 3,86 \cdot 5$ \\
\hline
\end{tabular}

${ }^{*}$ For children $<5$ years is mother's educational level. 


\section{Prevalence of malnutrition (overnutrition and undernutrition) in children ( $<5$ years)}

Table 2 and the Supplementary Fig. 1 shows the prevalence of malnutrition (overnutrition and undernutrition) by SES, maternal educational level and ethnicity in multivariable linear regression models. In children, the highest prevalence of malnutrition was from anaemia (27.4\%), followed by stunting (13.8\%), overweight/obesity (5.2\%) and wasting $(1.2 \%)$. In the low SES category, the prevalence of overweight/obesity was 1.4 times lower than that in the high SES category. In contrast, the prevalence of wasting, stunting and anaemia were $1.1,1.4$ and 1.3 times higher, respectively, in the low SES category than in the high SES category. Similarly, the prevalence of overweight/obesity in children was 1.6 times lower when the mother had a low educational level than when the mothers had the highest educational level. However, the prevalence of wasting, stunting and anaemia was $1.3,1.8$ and 1.0 times higher, respectively, in the low educational level than in the higher levels of education. Furthermore, indigenous children demonstrated a higher prevalence of overweight/ obesity, stunting and anaemia than their counterparts from other ethnicities. Afro-Colombian exhibited a lower prevalence of overweight/obesity and stunting than their counterparts.

\section{Prevalence of malnutrition in non-pregnant adolescent women (11-19years)}

In adolescent women, the highest prevalence of malnutrition was from overweight/obesity. In the multivariate lineal regression models, the prevalence of overweight/obesity, short stature and anaemia was 1.1, 1.5 and 2.2 times higher, respectively, in the low SES category than in the highest SES category. Similarly, the prevalence of all indicators of malnutrition (i.e. overweight/obesity, wasting and short stature) was higher in adolescents of mothers with lowest educational level than in those adolescents of mothers with higher educational level. Furthermore, indigenous non-pregnant adolescent women had a higher prevalence of overweight/obesity and short stature, while AfroColombian women had a higher prevalence of wasting and anaemia than their counterparts.

\section{Prevalence of malnutrition in non-pregnant adult women (20-49years)}

In adult women, the highest prevalence of malnutrition was from overweight/obesity. Nevertheless, the prevalence of overweight/obesity in adult women was $64.2 \%$ higher ( 2.8 times) than in adolescent women. In multivariable linear regression models, adult women with a lower SES had higher prevalence of wasting, short stature and anaemia than their counterparts. Similarly, adult women with lower educational level had a higher prevalence in all indicators of malnutrition. Furthermore, indigenous adult women had a higher prevalence of short stature, while Afro-Colombian women had a higher prevalence of overweight/obesity, wasting and anaemia than their counterparts.

\section{Discussion}

The current study provides evidence of socio-economic inequalities in Colombia reflected by differences in the prevalence of malnutrition. SES, maternal educational level and ethnicity are conditions that reflect this inequity. Children $<5$ years in the lowest SES category had the highest prevalence of undernutrition and the lowest prevalence of overweight/obesity. This type of inequality has been observed in other developing countries such as Iran and Haiti ${ }^{(30,31)}$. However, in developed countries, the highest prevalence of overweight is observed in low SEP groups ${ }^{(32)}$. Childhood undernutrition (stunting and nutritional anaemia) in developed countries is, however, not a public health concern. Malnutrition still affects children from developing countries, especially in Africa, South Asia and Oceania (excluding Australia and New Zealand), where the prevalence of stunting is as high as $38.3 \%{ }^{(33)}$, and anaemia is a severe public health problem ${ }^{(34)}$. The latter prevalence is a direct reflection of the inequity between developed and developing countries, which may be associated with differences in socioeconomic conditions.

From the current analysis, a special concern is that Colombian non-pregnant women of all ages from the low SES category and lower educational level exhibited the highest prevalence of being both overweight and suffering from anaemia. The anaemia result is not surprising because it is widely accepted that childbearing women are a vulnerable group due to menstruation ${ }^{(35)}$. Likewise, the prevalence of overweight in women of low SES has been reported in developing countries ${ }^{(10)}$.

Indigenous people and/or those Afro-Colombian had the highest prevalence of undernutrition (i.e. wasting, stunting and anaemia). A similar finding was observed in non-pregnant woman between 11 and 49 years with a low SES for conditions of malnutrition (over- and undernutrition). Thus, it is necessary to highlight the importance of analysing epidemiologic data with inequality as the focus to identify vulnerable populations.

The coexistence of conditions related to both over- and undernutrition at the population level, which has been identified as $\mathrm{DBM}^{(1)}$, should be highlighted. Further, DBM has been observed at the family and individual levels. In Colombia, the prevalence of DBM at the family level is $5.1 \%$, while it is $0.1 \%$ at the individual level in children under 5 years and is $3.4 \%$ in non-pregnant 13 -49-years-olds ${ }^{(19)}$. Despite the low DBM prevalence reported, a national average may mask inequities related to DBM. In the current study, children with a low SES, mothers with low levels of education and indigenous peoples, and those Afro-Colombian had a higher prevalence of wasting, stunting and anaemia 


\section{Public Health Nutrition}

Table 2 Prevalence of malnutrition (overnutrition and undernutrition) by socioeconomic status (SISBEN), maternal educational level and ethnicity in Colombia (ENSIN 2010)

\begin{tabular}{|c|c|c|c|c|c|c|c|c|c|c|c|c|c|c|}
\hline \multirow[b]{3}{*}{ Sociodemographic variables* } & & & \multicolumn{6}{|c|}{ Overnutrition§ } & \multicolumn{6}{|c|}{ Undernutrition§ } \\
\hline & \multicolumn{2}{|c|}{ Total $n \ddagger$} & \multicolumn{2}{|c|}{ Overweightll } & \multicolumn{2}{|c|}{ Obesityף } & \multicolumn{2}{|c|}{$\begin{array}{l}\text { Overweight/ } \\
\text { obesity }^{\star \star}\end{array}$} & \multicolumn{2}{|c|}{$\begin{array}{c}\text { Wasting/ } \\
\text { underweight†† }\end{array}$} & \multicolumn{2}{|c|}{$\begin{array}{l}\text { Stunting/short } \\
\text { stature } \ddagger \ddagger\end{array}$} & \multicolumn{2}{|c|}{ Anaemiaß§ } \\
\hline & $n$ & $\%$ & $\%$ & $95 \% \mathrm{Cl}$ & $\%$ & $95 \% \mathrm{Cl}$ & $\%$ & $95 \% \mathrm{Cl}$ & $\%$ & $95 \% \mathrm{Cl}$ & $\%$ & $95 \% \mathrm{Cl}$ & $\%$ & $95 \% \mathrm{Cl}$ \\
\hline \multicolumn{15}{|l|}{ Children $<5$ years } \\
\hline \multicolumn{11}{|l|}{ Socioeconomic status } & $13 \cdot 8$ & $13 \cdot 0,14 \cdot 5$ & $27 \cdot 4$ & $26 \cdot 0,28 \cdot 8$ \\
\hline Low (sisben 1) & 11690 & $59 \cdot 2$ & $3 \cdot 7$ & $3 \cdot 1,4 \cdot 2$ & $0 \cdot 8$ & $0.5,1.0$ & 4.4 & $3 \cdot 8,5 \cdot 0$ & 1.5 & $1.1,1.9$ & $16 \cdot 0$ & $14 \cdot 9,17 \cdot 2$ & $31 \cdot 1$ & $29 \cdot 1,33 \cdot 1$ \\
\hline Medium (sisben 2-3) & 4119 & $20 \cdot 9$ & $4 \cdot 6$ & $3 \cdot 7,5 \cdot 4$ & $1 \cdot 2$ & $0 \cdot 7,1.6$ & $5 \cdot 7^{*}$ & $4 \cdot 7,6 \cdot 7$ & $0 \cdot 7^{*}$ & $0.3,1 \cdot 0$ & $11 \cdot 1^{*}$ & $9 \cdot 6,12 \cdot 6$ & $24 \cdot 4^{*}$ & $21 \cdot 7,27 \cdot 1$ \\
\hline High (sisben 4 or + ) & 3925 & $19 \cdot 9$ & $4 \cdot 7^{*}$ & $3 \cdot 8,5 \cdot 5$ & $1.4^{*}$ & $0 \cdot 9,2 \cdot 0$ & $6 \cdot 1^{*}$ & $5 \cdot 1,7 \cdot 1$ & 0.9 & $0.5,1.4$ & $11 \cdot 7^{\star}$ & $10 \cdot 3,13 \cdot 1$ & $23.9^{\star}$ & $21 \cdot 1,26 \cdot 8$ \\
\hline \multicolumn{15}{|l|}{ Mother's educational level|III } \\
\hline Low (0-6 years) & 6059 & $30 \cdot 7$ & $3 \cdot 3$ & $2 \cdot 6,3 \cdot 9$ & 0.6 & $0.3,0.8$ & 3.7 & $3 \cdot 1,4 \cdot 6$ & 1.4 & $0.9,1 \cdot 8$ & $18 \cdot 1$ & $16 \cdot 7,19 \cdot 6$ & $26 \cdot 7$ & $24 \cdot 1,29 \cdot 2$ \\
\hline Medium (7-12 years) & 9345 & $47 \cdot 4$ & $4 \cdot 4^{*}$ & $3 \cdot 9,5 \cdot 0$ & $1 \cdot 2^{*}$ & $0.9,1.5$ & $5 \cdot 6^{*}$ & $50,6 \cdot 2$ & $1 \cdot 1$ & $0.8,1.4$ & $12 \cdot 7^{*}$ & $11 \cdot 7,13 \cdot 7$ & $29 \cdot 0$ & $27 \cdot 1,30 \cdot 9$ \\
\hline High (>12 years) & 2880 & $14 \cdot 6$ & $4 \cdot 6^{\star}$ & $3 \cdot 6,5 \cdot 7$ & $1 \cdot 3^{*}$ & $0.7,1.9$ & $5 \cdot 9^{*}$ & $4 \cdot 7,7 \cdot 1$ & $1 \cdot 1$ & $0.5,1.6$ & $10 \cdot 1^{*}$ & $8 \cdot 5,17 \cdot 7$ & $26 \cdot 0$ & $22 \cdot 5,29 \cdot 5$ \\
\hline \multicolumn{15}{|l|}{ Ethnicity } \\
\hline Indigenous & 2606 & $13 \cdot 2$ & $7 \cdot 1$ & $5 \cdot 2,8 \cdot 9$ & 0.6 & $0.2,1 \cdot 0$ & $7 \cdot 7$ & $5 \cdot 8,9 \cdot 6$ & 0.9 & $0.2,1.5$ & $27 \cdot 3$ & $22 \cdot 9,31 \cdot 7$ & 31.9 & $26 \cdot 1,37 \cdot 7$ \\
\hline Black/Mulatto/Afro-Colombian & 2183 & $11 \cdot 1$ & $3 \cdot 5^{\star}$ & $2 \cdot 6,4.5$ & 0.7 & $0 \cdot 3,1 \cdot 1$ & $4 \cdot 3^{*}$ & $3 \cdot 2,5 \cdot 3$ & 1.9 & $1 \cdot 0,2 \cdot 8$ & $10 \cdot 9^{*}$ & $8.9,12 \cdot 9$ & 33.0 & $29 \cdot 2,36 \cdot 8$ \\
\hline Other ethnicity & 14945 & $75 \cdot 7$ & $4.0 \dagger$ & $3 \cdot 6,4 \cdot 5$ & $1 \cdot 1^{*} \dagger$ & $0.9,1 \cdot 3$ & $5 \cdot 1 \dagger$ & $4 \cdot 6,5 \cdot 6$ & $1 \cdot 1$ & $0.9,1.4$ & $13 \cdot 4^{*} \dagger$ & $12 \cdot 6,14 \cdot 2$ & $26 \cdot 8 \dagger$ & $25 \cdot 3,28 \cdot 4$ \\
\hline \multicolumn{15}{|l|}{ Women $11-19$ years } \\
\hline \multicolumn{15}{|l|}{ Socioeconomic status } \\
\hline Medium & 3567 & $21 \cdot 2$ & 13.7 & $12 \cdot 2,15 \cdot 2$ & $2 \cdot 9$ & $2 \cdot 2,3 \cdot 6$ & $16 \cdot 6$ & $14 \cdot 9,18 \cdot 2$ & $\begin{array}{l}2.0 \\
1.5\end{array}$ & $\begin{array}{l}1.5,2 \cdot 4 \\
0.0,2 \cdot 0\end{array}$ & $\begin{array}{l}12 \cdot 4 \\
10 \cdot 6^{*}\end{array}$ & $\begin{array}{r}11 \cdot 4,13 \cdot 5 \\
9 \cdot 1,12 \cdot 1\end{array}$ & $\begin{array}{c}10 \cdot 2 \\
6 \cdot 1^{*}\end{array}$ & $\begin{array}{l}8 \cdot 7,11 \cdot 7 \\
4 \cdot 4,7 \cdot 7\end{array}$ \\
\hline High & 4221 & $25 \cdot 1$ & $12 \cdot 8$ & $11.5,14 \cdot 1$ & $2 \cdot 8$ & $2 \cdot 2,3 \cdot 5$ & $15 \cdot 6$ & $14 \cdot 2,17 \cdot 1$ & 1.6 & $1 \cdot 1,2 \cdot 2$ & $8 \cdot 4^{*} \dagger$ & $7.3,9.6$ & $4 \cdot 7^{*}$ & $3 \cdot 2,6 \cdot 2$ \\
\hline \multicolumn{15}{|l|}{ Mother's educational level|IIII } \\
\hline Low (0-6 years) & 3163 & $18 \cdot 8$ & $13 \cdot 0$ & $11 \cdot 3,14 \cdot 7$ & $3 \cdot 2$ & $2 \cdot 3,4 \cdot 1$ & $16 \cdot 2$ & $14 \cdot 3,18 \cdot 1$ & $2 \cdot 1$ & $1.4,2.9$ & $17 \cdot 9$ & $15 \cdot 8,19 \cdot 9$ & 8.9 & $6 \cdot 3,11 \cdot 6$ \\
\hline Medium (7-12 years) & 11418 & $67 \cdot 8$ & $14 \cdot 2$ & $13 \cdot 4,15 \cdot 1$ & $2 \cdot 8$ & $2 \cdot 4,3 \cdot 2$ & $17 \cdot 0$ & $16 \cdot 1,17 \cdot 9$ & 1.7 & $1 \cdot 4,2 \cdot 1$ & $9 \cdot 6^{*}$ & & 7.4 & $6 \cdot 4,8.4$ \\
\hline High ( $>12$ years) & 1218 & $7 \cdot 2$ & $9 \cdot 4^{*} \dagger$ & $7 \cdot 4,11 \cdot 3$ & $2 \cdot 5$ & $1 \cdot 3,3 \cdot 8$ & $11.9^{*} \dagger$ & $9 \cdot 6,14 \cdot 3$ & $0.8^{*} \dagger$ & $0.8,1.4$ & $7 \cdot 7^{*}$ & $5 \cdot 3,10 \cdot 0$ & $10 \cdot 7$ & $6 \cdot 6,14.9$ \\
\hline \multicolumn{15}{|l|}{ Ethnicity } \\
\hline Indigenous & 1915 & 11.4 & $17 \cdot 2$ & $14 \cdot 0,20 \cdot 4$ & $2 \cdot 0$ & $0.8,3 \cdot 1$ & $19 \cdot 2$ & $15 \cdot 7,22 \cdot 5$ & 0.4 & $0.0,0.1$ & $31 \cdot 2$ & $25 \cdot 6,36 \cdot 8$ & $10 \cdot 2$ & $5 \cdot 6,14 \cdot 7$ \\
\hline Black/Mulatto/Afro-Colombian & 1701 & $10 \cdot 1$ & $14 \cdot 2$ & $12 \cdot 0,16 \cdot 3$ & $3 \cdot 9^{*}$ & $2 \cdot 7,5 \cdot 0$ & $18 \cdot 0$ & $15 \cdot 7,20 \cdot 4$ & $2 \cdot 0^{*}$ & $1 \cdot 0,3 \cdot 0$ & $6 \cdot 0^{*}$ & $4 \cdot 1,7 \cdot 8$ & $12 \cdot \overline{7}$ & $9 \cdot 1,16 \cdot 2$ \\
\hline Other ethnicity & 13215 & 78.5 & $13 \cdot 3^{*}$ & $12 \cdot 5,14 \cdot 1$ & $2 \cdot 7$ & $2 \cdot 4,3 \cdot 1$ & $16 \cdot 1$ & $15 \cdot 2,16 \cdot 9$ & $1 \cdot 8^{*}$ & $1 \cdot 5,2 \cdot 1$ & $10 \cdot 4^{*} \dagger$ & $9 \cdot 6,11 \cdot 2$ & $7.0 \dagger$ & $6 \cdot 1,8 \cdot 0$ \\
\hline \multicolumn{15}{|l|}{ Women $20-49$ years } \\
\hline \multicolumn{13}{|l|}{ Socioeconomic status } & & $11 \cdot 5,13 \cdot 3$ \\
\hline Low & 17637 & $40 \cdot 0$ & $30 \cdot 1$ & $29 \cdot 1,31 \cdot 1$ & $15 \cdot 6$ & $14 \cdot 8,16 \cdot 4$ & $45 \cdot 7$ & $44 \cdot 6,46 \cdot 7$ & 3.7 & $3 \cdot 3,4 \cdot 1$ & $13 \cdot 4$ & $12 \cdot 6,14 \cdot 2$ & $14 \cdot 2$ & $12 \cdot 6,15 \cdot 7$ \\
\hline Medium & 10298 & $23 \cdot 4$ & 31.5 & $30 \cdot 3,32 \cdot 7$ & $16 \cdot 7$ & $15 \cdot 8,17 \cdot 6$ & $48 \cdot 2^{*}$ & $46 \cdot 9,49 \cdot 4$ & $2 \cdot 8^{*}$ & $2 \cdot 4,3 \cdot 2$ & $11 \cdot 5^{\star}$ & $10 \cdot 7,12 \cdot 3$ & $9 \cdot 9^{*}$ & $8 \cdot 3,11.5$ \\
\hline High & 16116 & $36 \cdot 6$ & $31 \cdot 1$ & $30 \cdot 2,32 \cdot 0$ & $15 \cdot 1 \dagger$ & $14 \cdot 4,15 \cdot 8$ & $46 \cdot 2 \dagger$ & $45 \cdot 2,47 \cdot 2$ & $2 \cdot 3^{*}$ & $1 \cdot 9,2 \cdot 6$ & $10 \cdot 5^{\star}$ & $9 \cdot 9,11 \cdot 1$ & $12 \cdot 0$ & $10 \cdot 6,13.5$ \\
\hline \multicolumn{15}{|l|}{ Education levell|III } \\
\hline Low $(0-6$ y) & 13779 & $31 \cdot 3$ & 33.9 & $32 \cdot 8,35 \cdot 0$ & $21 \cdot 0$ & $20 \cdot 1,21 \cdot 9$ & 54.9 & $53 \cdot 7,56 \cdot 0$ & $2 \cdot 1$ & $1 \cdot 8,2 \cdot 5$ & $18 \cdot 3$ & $17 \cdot 4,19 \cdot 3$ & $13 \cdot 8$ & $12 \cdot 0,15 \cdot 7$ \\
\hline Medium (7-12 y) & 18393 & $41 \cdot 8$ & $31 \cdot 3^{\star}$ & $30 \cdot 4,32 \cdot 1$ & $14 \cdot 9^{*}$ & $14 \cdot 2,15 \cdot 5$ & $46 \cdot 1^{*}$ & $45 \cdot 2,47 \cdot 0$ & $3 \cdot 2^{*}$ & $2 \cdot 8,3.5$ & $10 \cdot 3^{\star}$ & $9 \cdot 7,10 \cdot 8$ & $12 \cdot 5$ & $11 \cdot 1,13 \cdot 8$ \\
\hline High $(>12 y)$ & 9707 & $22 \cdot 0$ & $27 \cdot 0^{*} \dagger$ & $25 \cdot 7,28 \cdot 0$ & $11 \cdot 0^{*} \dagger$ & $10 \cdot 2,11 \cdot 8$ & $37 \cdot 9^{*} \dagger$ & $36 \cdot 6,39 \cdot 1$ & $3 \cdot 3^{*}$ & $2 \cdot 8,3 \cdot 7$ & $6 \cdot 8^{*} \dagger$ & $6 \cdot 1,7 \cdot 4$ & $10 \cdot 1^{*}$ & $8 \cdot 4,11 \cdot 8$ \\
\hline
\end{tabular}


compared with their counterparts. These results suggest that public policies should address all forms of malnutrition in the most vulnerable populations using multiple strategies.

In Colombia, strategies were implemented to achieve the United Nation's millennium developmental goals from 1990 to 2015, including the reduction of hunger ${ }^{(36)}$. Accordingly, in children $<5$ years, the prevalence of stunting decreased from $26 \cdot 1 \%$ in 1990 to $13.2 \%$ in 2010 , and the prevalence of underweight decreased from 8.6 to $3.4 \%$ in the same period ${ }^{(18)}$. However, as we observed in the current study, children with a low SES, mothers with a low level of education, indigenous people and those Afro-Colombian still demonstrated a significantly higher prevalence of wasting, stunting and anaemia compared with their counterparts. Conversely, the prevalence of overweight increased from $3.1 \%$ in 2005 to $5.2 \%$ in 2010 , which is consistent with micronutrient deficiencies ${ }^{(37)}$.

Evidence from the nutritional transition in Colombia indicates that although overweight/obesity continues to be more prevalent among high-income Colombian households, it is growing at a faster pace among the most economically disadvantaged ${ }^{(38)}$. Our study of non-pregnant adolescent and adult women (between 11 and 49 years) showed similar results, where those with a lower SES and low levels of education experienced the worst scenario, namely, having the highest prevalence for both types of malnutrition (undernutrition (wasting, stunting and anaemia) and overweight/obesity). Accordingly, a recent analysis has also shown that the DBM in Colombia coexists at the national, household and intra-individual levels ${ }^{(19,39,40)}$. Furthermore, the double DBM has been associated with poverty in developing countries ${ }^{(41)}$.

Some of the social determinants of malnutrition in Latin America are SES, level of education, sex and ethnicity. These determinants explain nearly all situations of marginalisation or exclusion in societies and serve as strong markers for the junctures of malnutrition ${ }^{(42)}$. Our results are consistent with results from a study conducted a decade ago that investigated the roles individual, household and community level characteristics in the socioeconomic inequalities of malnutrition among children and adolescents in Colombia. In that study, maternal education and access to sanitation explained stunting, while maternal and household characteristics explained the socioeconomic disparities of overweight ${ }^{(20)}$. However, in the current study, ethnicity was, for the first time, included as a factor that demonstrated an association with the highest prevalence of malnutrition.

Our results represent an important discussion point for the public health agenda in Colombia. The country is presently experiencing a historical moment of peace after more than half a century of conflict that is believed to have cost the lives of 220000 people and displaced more than six million $^{(43)}$. The consequences of that conflict created an environment of social inequality, where deaths from undernutrition (wasting) among the most socially disadvantaged 
children are still occurring ${ }^{(44,45)}$. Concurrently, the population in the main cities experience the $\mathrm{DBM}^{(19)}$. Thus, it is an important and historical moment in Colombia, where resources previously co-opted for use in the conflict, must now shift to agricultural programmes, social reconstruction and improving the nutritional status of the population. This shift must take into account the idea that 'food is a right, not a commodity' and focus on supplying healthy food products for the entire population, especially to those who are the most disadvantaged (i.e. children, non-pregnant women and indigenous and Afro-Colombian living in low socioeconomic conditions).

Actions undertaken by The National Policy on Food and Nutrition Security from 2014 to 2018 by the 'Instituto Colombiano de Bienestar Familiar (ICBF)' are focused on ensuring that the population has access to and consumes food in a stable and timely manner and with sufficient quantity, variety, quality and safety ${ }^{(46)}$. Important strengths of the current policies to prevent undernutrition or overweight in Colombia appear to be their inter-sectorial nature, their focus on well-being and quality of life as a whole and not on individual aspects of health or nutritional status, as well as an emphasis on prevention through lifestyle and community interventions ${ }^{(47)}$. However, it is important to underscore that current policies require adequate implementation with the coordination of entities working both sides of the problem to optimise resources and ensure that specific policies are not contributing to worsening other health problems.

The main strength of the current study is the use of a nationally representative sample that includes anthropometric and sociodemographic indicators. The results of our study can be used as a baseline for the nutritional conditions of vulnerable populations previous to the current peace process and will allow us to contrast that situation with nationally representative samples following the implementation of the peace agreements, social reconstruction and the end of conflict in Colombia. The main limitation is the cross-sectional nature of the study, which does not enable us to infer causality/directionality of the association between sociodemographic status and malnutrition. However, these results represent the first study with nationally representative data that show the socioeconomic inequalities of malnutrition in vulnerable populations from Colombia.

\section{Conclusion}

The current study showed evidence of socioeconomic inequalities of malnutrition (under- or overnutrition) in Colombian children $<5$ years and non-pregnant (adolescent and adult) women. These results suggest that public policies regarding nutrition must shift focus from undernutrition programmes to multiple strategies to address all forms of malnutrition in the most vulnerable populations.

\section{Acknowledgements}

Acknowledgements: The 'Instituto Colombiano de Bienestar Familiar' (ICBF) and PROFAMILIA provided support and allowed the use of ENDS/ENSIN data base. The authors would like to thank the Latin American Nutrition Leadership Program (LILANUT Program) for the coordination of the project 'Malnutrition in all its forms for wealth, education and ethnicity in Latin America: Who is affected the most?', to which this article makes part. Financial support: The current study has financial support from the 'grupo de determinantes sociales y economicos de la nutrición', of the school of nutrition and dietetics from the University of Antioquia. Conflict of interest: The authors declare that there is no conflict of interest regarding the publication of this article. Authorship: G.C. took care of data management and analyses. G.C., E.P., D.G., O.S. and L.G. interpreted the data. G.C. wrote the first draft of the manuscript. All authors read, edited and approved the final manuscript. Ethics of buman subject participation: Not applicable.

\section{Supplementary material}

For supplementary material accompanying this paper visit https://doi.org/10.1017/S1368980019004257.

\section{References}

1. WHO (2017) WHO | Double Burden of Malnutrition. Geneva: World Health Organization. http://www.who.int/ nutrition/double-burden-malnutrition/en/ (accessed July 2017).

2. WHO (2011) The Global Prevalence of Anaemia in 2011, Geneva: WHO Library Cataloguing-in-Publication Data.

3. World Health Organization (2017) WHO | Work Programme of the United Nations Decade of Action on Nutrition (2016-2025). World Health Organization. http://www.who.int/nutrition/ decade-of-action/workprogramme-2016to2025/en/ (accessed June 2017).

4. The Condition of Education - Glossary. https://nces.ed.gov/ programs/coe/glossary.asp (accessed May 2019).

5. Basto-Abreu A, Barrientos-Gutiérrez T, Zepeda-Tello R et al. (2018) The relationship of socioeconomic status with body mass index depends on the socioeconomic measure used. Obesity (Silver Spring) 26, 176-184.

6. Marmot MG (2005) The Status Syndrome: How Social Standing Affects Our Health and Longevity. New York: Henry Holt.

7. Krieger N (2002) Glosario de epidemiología social. Rev Panam Salud Pública 11, 480-490. Organización Panamericana de la Salud.

8. Zhernakova YV, Zheleznova EA, Chazova IE et al. (2018) The prevalence of abdominal obesity and the association with socioeconomic status in Regions of the Russian Federation, the results of the epidemiological study - ESSE-RF. Ter Arkh 90, 14-22.

9. Najafi F, Pasdar Y, Hamzeh B et al. (2018) Measuring and decomposing socioeconomic inequalities in adult obesity in Western Iran. J Prev Med Public Health 51, 289-297. Korean Society for Preventive Medicine. 
10. Djalalinia S, Peykari N, Qorbani M et al. (2015) Inequality of obesity and socioeconomic factors in Iran: a systematic review and meta-analyses. Med J Islam Repub Iran 29, 241. Iran University of Medical Sciences.

11. Berkman LF \& Kawachi I (2000) Social Epidemiology. New York: Oxford University Press.

12. Lloyd-Sherlock P (2009) Social policy and inequality in Latin America: a review of recent trends. Soc Policy Adm 43, 347-363. Blackwell Publishing Ltd.

13. Popkin BM, Adair LS \& Ng SW (2012) Global nutrition transition and the pandemic of obesity in developing countries. Nutr Rev 70, 3-21.

14. Uauy R \& Monteiro CA (2004) The challenge of improving food and nutrition in Latin America. Food Nutr Bull 25, $175-182$.

15. VII Latin American Workshop on Leadership in Nutrition (2018) Proposal and actions to decrease malnutrition in Latin America and the Caribbean. Food Nutr Bull 39, 290295.

16. Economic Commission for Latin America and the Caribbean (ECLAC) Preliminary Overview of the Economies of Latin America and the Caribbean. http://repositorio.cepal.org/ bitstream/handle/11362/40826/37/1601259BP_Colombia_en. pdf (accessed June 2017)

17. Pobreza Monetaria y Multidimensional en Colombia (2016) https://www.dane.gov.co/index.php/estadisticas-por-tema/ pobreza-y-condiciones-de-vida/pobreza-y-desigualdad/ pobreza-monetaria-y-multidimensional-en-colombia-2016 (accessed July 2017).

18. Instituto Colombiano de Bienestar Familiar (2010) Encuesta Nacional de la Situación Nutricional en Colombia (ENSIN): Instituto Nacional de Salud; Bogotá, Colombia.

19. Sarmiento OL \& Parra D (2014) The dual burden of malnutrition in Colombia. Am J Clin Nutr 100, Suppl. 6, 1628S1635 S.

20. Garcia S, Sarmiento OL, Forde I et al. (2013) Socio-economic inequalities in malnutrition among children and adolescents in Colombia: the role of individual-, household- and community-level characteristics. Public Health Nutr 16, 1703-1718.

21. UNHCR Indigenous People and Forced Displacement in Colombia. www.unhcr.org (accessed August 2019).

22. Barrero LA \& Barrero LAA (2011) Displaced Indigenous and Afro-Colombian populations in Bogotá. Trab Soc 0, 61-76.

23. ENDS (2010) Encuesta Nacional de Demografia y Salud. Bogota: Profamilia.

24. WHO Multicentre Growth Reference Study Group (2006) WHO child growth standards based on length/height, weight and age. Acta Paediatr Suppl 450, 76-85.

25. de Onis M \& Habicht JP (1996) Anthropometric reference data for international use: recommendations from a World Health Organization Expert Committee. Am J Clin Nutr 64, 650-658. American Society for Nutrition.

26. World Health Organization \& Department of Nutrition for Health and development (2001) Iron Deficiency Anaemia: Assessment, Prevention and Control: A Guide for Programme Managers. Geneva: World Health Organization.

27. WHO Multicentre Growth Reference Study Group (2006) Reliability of anthropometric measurements in the WHO Multicentre Growth Reference study. Acta Paediatr Suppl 450, 38-46.

28. WHO (1995) WHO | Physical Status: The Use and Interpretation of Anthropometry. Geneva: World Health Organization.

29. Departamento Nacional de Planeación Colombia (2001) Documentos CONPES. https://www.sisben.gov.co/sisben/ Paginas/Documentos-CONPES.aspx (accessed June 2017).

30. Kelishadi R, Qorbani M, Heshmat R et al. (2018) Socioeconomic inequality in childhood obesity and its determinants: a Blinder-Oaxaca decomposition. J Pediatr (Rio J) 94, 131-139. Elsevier.
31. El Mabchour A, Delisle H, Vilgrain C et al. (2016) Obésité abdominale et autres biomarqueurs de risque cardiométabolique: influence du niveau socioéconomique et du mode de vie dans deux populations noires apparentées, Cotonou (Bénin) et Port-au-Prince (Haïti). Pan Afr Med J 24, 306.

32. Biro S, Williamson T, Leggett JA et al. (2016) Utility of linking primary care electronic medical records with Canadian census data to study the determinants of chronic disease: an example based on socioeconomic status and obesity. BMC Med Inform Decis Mak 16, 32. BioMed Central.

33. de Onis M, Dewey KG, Borghi E, et al. (2013) The World Health Organization's global target for reducing childhood stunting by 2025: rationale and proposed actions. Matern Child Nutr 9, 6-26.

34. McLean E, Cogswell M, Egli I et al. (2009) Worldwide prevalence of anaemia, WHO vitamin and mineral nutrition information system, 1993-2005. Public Health Nutr 12, 444-454.

35. Micronutrients I of M (US) P on (2001) Dietary Reference Intakes for Vitamin A, Vitamin $K$, Arsenic, Boron, Chromium, Copper, Iodine, Iron, Manganese, Molybdenum, Nickel, Silicon, Vanadium, and Zinc. Diet. Ref. Intakes Vitam. A, Vitam. K, Arsenic, Boron, Chromium, Copper, Iodine, Iron, Manganese, Molybdenum, Nickel, Silicon, Vanadium, Zinc. Washington, DC: National Academies Press.

36. Bogotá DC (2005) Conpes Social. Metas y estrategias de Colombia para el logro de los objetivos del desarrollo del Milenio - 2015. http://www.minambiente.gov.co/images/ normativa/conpes/2005/Conpes_0091_2005.pdf (accessed July 2017).

37. Cediel Giraldo G, Castaño Moreno E \& Gaitán Charry D (2016) Doble carga de malnutrición durante el crecimiento: ¿una realidad latente en colombia? Rev Salud Pública 18, 656.

38. Parra DC, Iannotti L, Gomez LF et al. (2015) The nutrition transition in Colombia over a decade: a novel household classification system of anthropometric measures. Arch Public Health 73, 12. BioMed Central.

39. Parra DC, Gomez LF, Iannotti L et al. (2018) Maternal and familial correlates of anthropometric typologies in the nutrition transition of Colombia, 2000-2010. Public Health Nutr 21, 2584-2594.

40. Parra DC, Gomez LF, Iannotti L et al. (2018) Multilevel correlates of household anthropometric typologies in Colombian mothers and their infants. Glob Health Epidemiol Genomics 3, e6.

41. Delisle H, Batal M, Renier G et al. (2016) The double burden of malnutrition associated with poverty. Lancet 387, 2504-2505. Elsevier.

42. Jiménez-Benítez D, Rodríguez-Martín A \& JiménezRodríguez R (2010) Análisis de determinantes sociales de la desnutrición en Latinoamérica. Nutr Hosp 35, 18-25.

43. The Guardian (2016) Colombia's half-century of conflict that led to historic peace deal.

44. Quiroga EF (2012) Death rate by malnutrition in children under the age of five, Colombia. Biomedica 32, 499-509.

45. Instituto Nacional de Salud de Colombia (2017) Boletín Epidemiológico semanal. 1-24. http://www.ins.gov.co/ boletin-epidemiologico/Boletn Epidemiolgico/2017 Boletín epidemiológico semana 25 NUEVO.pdf (accessed August 2017).

46. Departamento para la prosperidad social Instituto Colombiano de Bienestar Familiar (2017). http://www.icbf. gov.co/portal/page/portal/PortalICBF/bienestar/nutricion/ pnsan (accessed August 2017).

47. International food policy Research Institute (2015) Global Nutrition Report 2015: Actions and Accountability to Advance Nutrition and Sustainable Development. Washington, DC: International food policy Research Institute. 